\title{
Research Based on Fault Self-diagnosis and Repair System of "Internet + Medical Equipment"
}

\author{
Jiaxiong Wen
}

\author{
Sichuan Information Technology College
}

Key words: Internet +; medical equipment; fault self-diagnosis; fault repair; Internet of Things

\begin{abstract}
Based on the fault self-diagnosis and repair application system of "Internet + medical equipment", with maintenance and faults of medical equipment as the research object, integrating such key technology as Internet + , Internet of Things, big data and single chip microcomputer control, it is designed to develop an application system which can realize online or offline automatic detection, fault location and self-repair functions of medical equipment, 。
\end{abstract}

1. The necessity of research

(1) The research is the only way leading to informatization development of medical equipment maintenance and fault detection.

Medical equipment technology covers such disciplines as sound, light, electricity, machinery, semiconductor, software and network, moreover, demands strong technology integration capability.

(2) The research can effectively meet the quick response demand of modern medical equipment maintenance and ensure the immediacy, accuracy and reliability of medical diagnosis.

Modern medical equipment industry has been a high technology industry integrating multi-disciplines, a knowledge and capital intensive industry.

(3) The research can effectively reduce the economic burden of hospitals and patients.

As a matter of fact, the yearly maintenance expense for traditional medical equipment reaches up to $3 \% \sim 6 \%$ of the total machine price, becoming the huge economic burden of the hospital and being passed to patients.

2. Present research situation and development tendency at home and abroad

Such techniques as Internet + , big data, Internet of Things and cloud computation home and abroad are flourishing with the arrival of industrial 4.0 era, and the technique of fault self-diagnosis is increasingly mature, but the above techniques are generally independent of each other.

3. Intellectual property rights situation analysis of the research

At present, the pure "Internet +" technology and fault self-diagnosis technology are relatively mature at home and abroad.In terms of a single technology, research can generally be realized by means of modern electronic and information technology.

4. Application innovation of research

(1) Resource integration, system integration and high pertinence: the present "Internet +" technology and fault self-diagnosis technology are independent system and it is hard to realize the comprehensive utilization advantage of joint construction and sharing for maintenance resources of medical equipment.

(2) Realize "public entrepreneurship and multitude innovation" and greet industrial 4.0 era: the promotion and application of the research is not only consistent with the technical development trend of medical industry, but also fully respond to the national policy of "public entrepreneurship and multitude innovation”.

5. Technological innovation of research

The research group has carried out thorough investigation and studied diligently, conducting autonomous learning by virtue of the technical advantages in electronic information and medical equipment maintenance, achieving breakthrough in the aspects of product miniaturization, modularization and intellectualized design.

(1) Self-developed fault information database based on "Internet + " mode

In view of the open and interconnected joint construction and sharing requirements and modular design idea, fault information database based on "Internet +" mode is developed independently. 
(2) Self-developed self-diagnosis system for medical equipment

Collect equipment information data by means of time division and sharding. Look up and identify faults using "threshold relevance" principles, with high performance embedded processor S3C2440, low power consumption single chip microcomputer MSP430 and specialized DSP co-processor as the core, and research the unit circuit of the controller module by module.

6. Application prospects for the research

Take a certain grade A class 2 hospital in Guangyuan for example: the hospital uses 54 sets of equipment for fault self-diagnosis and repair system of medical equipment based on "Internet + " in total, with a value of 7.47 million yuan.

7. Economic benefits from the research

Considering the daily maintenance expense, with the yearly routine maintenance expense calculated as 0.1 million yuan, the average yearly maintenance expense after using the system will be: $0.12+0.1=0.22$ million yuan.

8. Social benefits from the research

The open and interconnected fault information database, experts and users communication platform are conducive to the secondary innovation and entrepreneurship of relevant staff of equipment maintenance, laying the stepping stone for the arrival of industrial 4.0 era.

9. Research objects

Complete the research investigation of fault self-diagnosis and repair system based on "Internet + medical equipment”, scheme demonstration, development, debugging and trial production of software and hardware system, and eventually form the practical new products.

2. Research contents

(1) Technical principles on which the research is based

The research is based on "Internet +" fault self-diagnosis and repair system of medical equipment, designed to solve problems in online or offline automatic detection, fault identification and location, fault alarm output and automatic repair for medical equipment of various models, mainly composed of resource sharing big database subsystem and fault detection subsystem.

1) Resource sharing big database subsystem

The core of the subsystem is the application of "Internet +" technology to realize the joint construction and sharing of such resources as technical documents and videos related to medical equipment, providing support data for the realization of fault detection, location and repair functions of equipment.

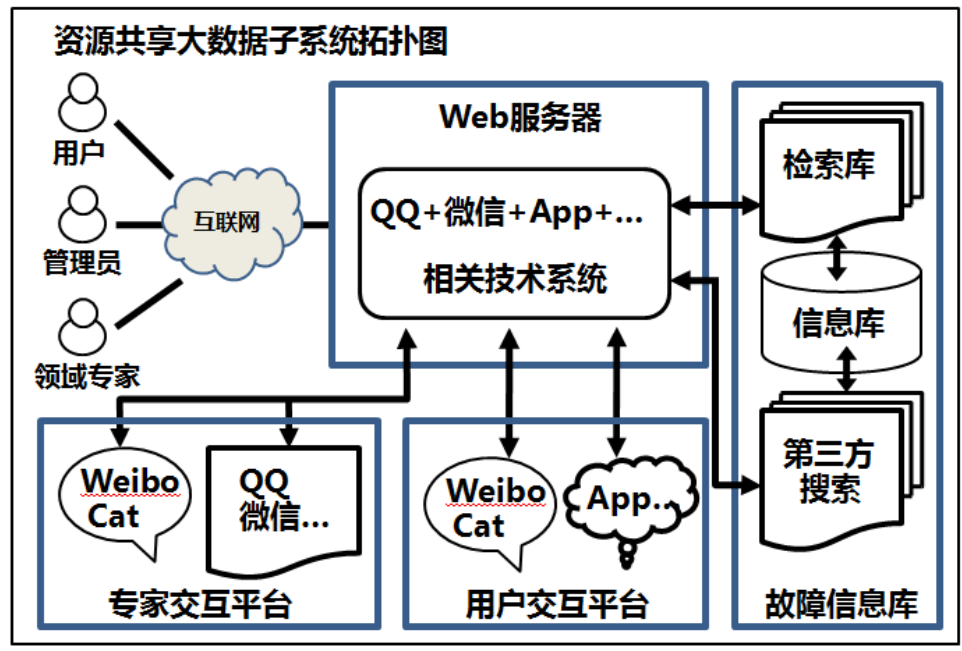




\begin{tabular}{|l|l|}
\hline 资源共享大数据子系统拓扑图 & Topological graph of resource sharing big \\
database subsystem \\
户 & User \\
管理员 & Administrator \\
互联网 & Internet \\
领域专家 & Field experts \\
Web 服务器 & Web server \\
微信 & WeChat \\
相关技术系统 & Relevant technical system \\
专家交互平台 & Experts interactive platform \\
用户交互平台 & Users interactive platform \\
检索库 & Search database \\
信息库 & Information database \\
第三方搜索 & Third party search \\
故障信息库 & Fault information database \\
\hline
\end{tabular}

FIG 1 Composition block diagram of resource sharing big database subsystem

Fault information database: this part is an innovative fault information "big data" library, mainly integrated by the users, administrators and field experts for medical equipment of various models through application of "Internet +" technology.

2) Fault detection subsystem

Its topological graph is shown in Figure 2. The subsystem can complete such functions of medical equipment of various models as online or offline automatic detection, fault identification and location, fault alarm output and automatic repair, with four working modes.

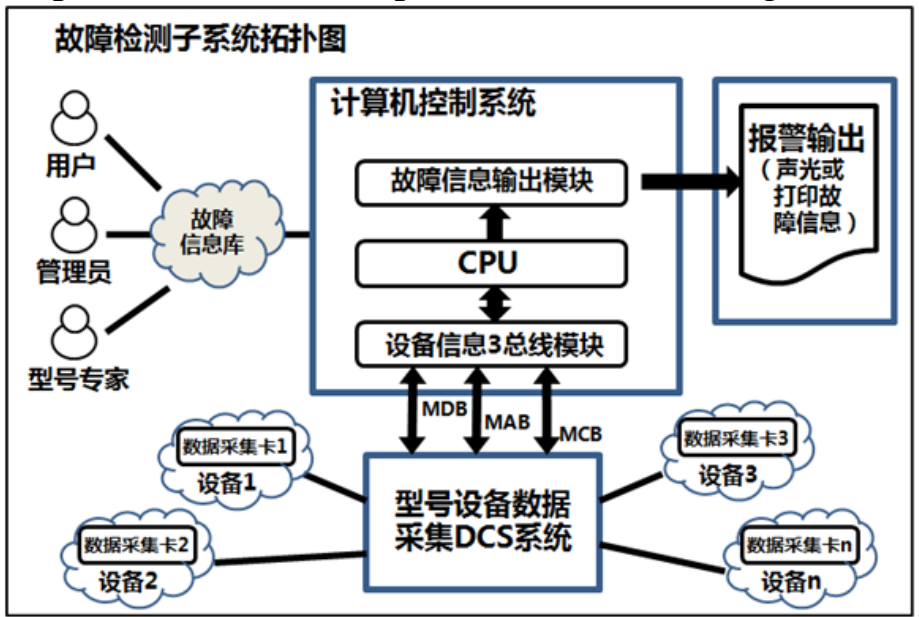

\begin{tabular}{|c|c|}
\hline $\begin{array}{l}\text { 故障检测子系统拓扑图 } \\
\text { 用户 } \\
\text { 管理员 } \\
\text { 型号专家 } \\
\text { 故障信息库 } \\
\text { 计算机控制系统 } \\
\text { 故障信息输出模块 } \\
\text { 设备信息 } 3 \text { 总线模块 } \\
\text { 数据采集卡 } 1 \\
\text { 设备 } 1 \\
\text { 数据采集卡 } 2 \\
\text { 设备 } 2 \\
\text { 型号设备数据采集 DCS 系统 } \\
\text { 数据采集卡 } 3 \\
\text { 设备 } 3 \\
\text { 数据采集卡 n } \\
\text { 设备 } \mathrm{n} \\
\text { 报警输出 (声光或打印故障信息) }\end{array}$ & $\begin{array}{l}\text { Topological graph of fault detection subsystem } \\
\text { User } \\
\text { Administrator } \\
\text { Model experts } \\
\text { Fault information database } \\
\text { Computer control system } \\
\text { Fault information output module } \\
\text { Equipment information } 3 \text { bus module } \\
\text { Data collection card } 1 \\
\text { Equipment } 1 \\
\text { Data collection card } 2 \\
\text { Equipment } 2 \\
\text { Model equipment data collection DCS system } \\
\text { Data collection card } 3 \\
\text { Equipment } 3 \\
\text { Data collection card n } \\
\text { Equipment } n \\
\text { Alarm output (acousto-optic or printing fault information) }\end{array}$ \\
\hline
\end{tabular}

FIG 2 Composition block diagram of fault detection subsystem

CPU judges whether there is any fault in the equipment, in case of any fault, checks the fault information and tries self-repair. The fault information output module outputs the fault point information to the smallest replaceable unit of the equipment. 
(2) Main research contents of the research

The research mainly focuses on the technologies of fault information database, computer control system and model equipment data collection DCS system, as well as the software and hardware design of the system.

1) Fault information database

Relying on such technical means as distributed processing, distributed database cloud storage and virtualization provided by cloud computing, efficient resource sharing technology provided by "big data" and "Internet of Things" is adopted to integrate such technical methods as Web technology, can conduct real-time maintenance, update and joint construction and sharing of the database resources.

2) Computer control system

The system applies modern computer/single chip microcomputer distributed control technology, with equipment information 3 bus module completing reading and storage of status information for equipment of various models in divided time.

3) Model equipment data collection DCS system

The data collection card of equipment is preset with sampling circuit to ensure normal operation for equipment of various models, so as to complete the real-time collection of equipment feature data.

10. Key technique of the research

(1) The equipment manufacturers and users apply efficient resource sharing technology provided by "big data" and "Internet of Things" and adopt such technical methods as innovative and integrated Web technology, online document technology and database, completing the functions of distributed control, management and cloud storage of distributed equipment data and achieving the function of integrating scattered information into open and interconnected big database.

(2) Fault self-diagnosis technique: after the equipment feature data collected by pre-processing DCS system are sent to the computer control system, "relevance" threshold criterion recognition is carried out between CPU and the threshold data in "threshold storage" and the status of equipment will be determined.Fault Fault self-diagnosis technique system provides four working modes: namely online single step detection, online cycle detection, offline single step detection and offline cycle detection.

1) Online single step detection mode: when equipment work online, a single detection of the state of specified equipment is used for detection of equipment with high fault rate;

2) Online cycle detection mode: when equipment work online, cycle detection of the state of all equipment is used for detection of very old equipment;

11. Technical route of the research

The development of technical route (see Figure 3) for the research shall abide by the following principles:

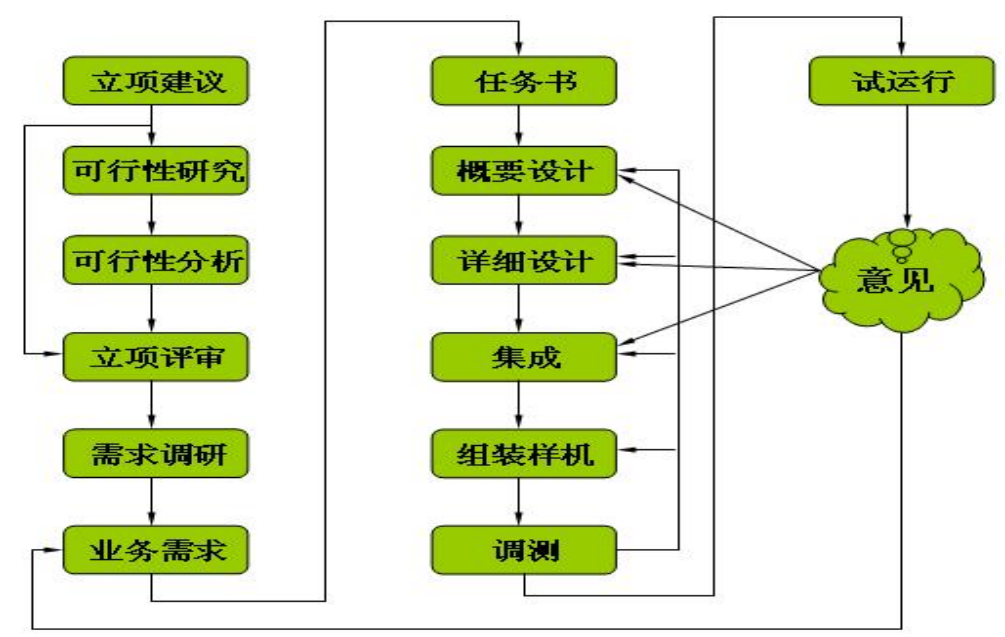




\begin{tabular}{|c|c|}
\hline 立项建议 & Project proposal \\
可行性研究 & Feasibility research \\
可行性分析 & Feasibility analysis \\
立项评审 & Project evaluation \\
需求调研 & Demand survey \\
业务需求 & Business requirement \\
任务书 & Assignment book \\
概要设计 & Preliminary design \\
详细设计 & Detailed design \\
集成 & Integration \\
组装样机 & Assembly of model equipment \\
调测 & Commissioning test \\
试运行 & Trial operation \\
意见 & Comments \\
\hline
\end{tabular}

FIG 3 Development of technical route diagram for the research

Normalization: conform to relevant international, national and industrial standards.

Practicability: the system is the scheme determined on the basis of deep research on electronic information and medical equipment industry for many years .

12. Application scheme of the research

After putting into operation, direct economic benefits will be obtained in the following two aspects: reduction of equipment maintenance cost and misdiagnosis rate.

\section{References}

[1]. Chen Hao; Integrated Management of Medical Equipment [D]; Southwest Jiaotong University; 2002

[2]. Wang Yuelei; Usability Design Research on Human-computer Interface of Medical Equipment [D]; Nanjing Forestry University; 2007

[3]. Chen Wei; Research on Medical Equipment Information Management Problems and Countermeasures [D]; Peking Union Medical College; 2014

[4]. Liu Yang; Design and Realization of Dynamically Configurable Medical Equipment Gateway [D]; Zhejiang University; 2012

[5]. Li Bing; Research on Medical Equipment Management System Based on RFID Technology [D]; Zhejiang University of Technology; 2008

[6]. Lv Lingxue; Design of Electrical Safety Analyzer for Medical Equipment [D]; Harbin University of Science and Technology; 2011 